\title{
The Evolution of Assessment within an Introductory Physics Course
}

\author{
http://dx.doi.org/10.3991/ijep.v3iS1.2393 \\ T.L. Larkin \\ American University, Washington, DC, USA
}

\begin{abstract}
This paper provides an overview of the evolution of an introductory physics course for non-majors entitled Physics for a New Millennium (PNM) at American University. Following a brief summary of the research and pedagogical framework for the course design, a summary of the course curriculum will be presented. A significant portion of the course curriculum provides students with an opportunity to experience all aspects of preparing, writing, and presenting a professional research paper in a conference setting. Following a description of the course curriculum, the specific structure for the conference paper activity will be outlined and highlights of student work will be shared with a focus on the spring 2012 class. The conference paper activity is assessed using authentic, formative strategies and will serve as one focus of this paper. To address the authentic assessment piece, a collection of strategies and methods will be shared that have been designed to key in on what and how students are learning throughout all phases of the paper writing process. These methods can be used as an alternative, or as a supplement to more traditional pencil and paper examinations, quizzes, and homework assignments. The thrust of the authentic assessment is to address any deficiencies in student learning while the learning is taking place. Exams and quizzes end up being "too little, too late" in terms of helping students correct any flaws in their understanding. Feedback from students relating to the paper writing experience will also be shared.
\end{abstract}

Index Terms - authentic assessment, formative assessment, innovations in physics learning, student writing.

\section{INTRODUCTION AND RESEARCH FRAMEWORK}

Studies on teaching methodologies have clearly demonstrated that traditional techniques often put students in a role of passive rather than active learning $[1-5]$. Traditional instructional methods have also been shown to be very inadequate in terms of promoting deep learning and long-term retention of important concepts [6 - 9]. Students in traditional classrooms acquire most of their knowledge through passive classroom lectures, textbook reading, and the internet. Passive learning often results in students merely trying to learn and regurgitate what they believe the teacher and textbook are telling them. A troubling fact is, after instruction, students often emerge from our classes with serious misconceptions [10 - 16]. Writing can be used to effectively help students confront their misconceptions. In addition, formal writing strategies can be used as an alternative method to help uncover what students are actually learning in "real time."

Using a writing approach to assist students in the learning process can provide a wealth of information while the actual learning is taking place. Traditional examinations and quizzes merely provide an assessment marker after a segment of material has been covered in class. While important as a marker for charting progress, these forms of assessment do little to uncover what is actually taking place in the mind of the learner. Astin [17] argues that as professors, we may think that we've given a very stimulating and thought-provoking lecture, without ever really knowing how much of it was actually understood by the students, how much was retained, or whatever other kinds of effects it may have had on the students. While traditional examinations and quizzes may provide faculty members with some information about what students are learning, this more summative type of feedback really comes too late for in terms of allowing students time to make any adjustments to their understanding. A carefully crafted writing activity or set of activities can provide a more formative and authentic assessment of student learning; and, give students and professors time to correct any misconceptions or flaws in reasoning as the learning is ongoing. A writing-based curriculum also serves as a more authentic roadmap to help chart how and what students are learning while the learning is taking place. This is in sharp contrast to other "postmortem" summative assessment measures.

In this paper, a summary of the curriculum devised for the course and the conference paper activity will be highlighted. A brief overview of the activity-based curriculum and the framework for the conference paper activity will be shared. Once the framework for the conference paper activity has been outlined, the strategies used to assess learning based on student writing activities will be presented. It is one thing to have students write a research paper in a class; and, it is quite another to assess student learning throughout the entire writing experience. Within the PNM course, assessment is done throughout all aspects of the writing process and is not based solely on the completed research paper. It is this critical assessment piece that this paper will address in some detail.

The particular writing-based curricular activity to be showcased in this paper involves a second-level physics course for non-majors. Before discussing the writing activity, some details about the course setting and student clientele will be presented.

\section{The Course SETTING}

This section will begin with a brief summary of the role that research in Physics Education has played in terms of the design of the PNM course. In addition, a brief description of the student clientele will be presented.

\section{A. Physics Education Research Informs Course Design}

Rebello [18] suggests that the essential goal of education is the transfer of learning. Research in the field of 
Physics Education continues to provide educators with a window through which an understanding of how students learn physics can be developed. Beichner [19] suggests that Physics Education Research (PER) is “... focused inquiry into what happens as students struggle to grasp and use the concepts of physics." Focused inquiry involves the use of a number of strategies - both qualitative and quantitative - that help bring to bear students' understanding about a select topic, or a set of topics within physics.

Redish [20] has provided a thoughtful collection of PER-based resources and tools which exemplify how focused inquiry has informed the physics education community. Knight [21] has also developed a set of classroom tools and techniques that are centered within an active-learning classroom environment. Mazur's Peer Instruction approach to physics learning offers a number of innovative ideas for physics instruction [22]. Resources such as these, as well as others to be described, serve to inform the pedagogical framework for the PNM course.

B. Additional Motivation for Course Design: Individual Styles of Learning

Hewson [23] suggests that when learning things they don't know, students try to make connections to what they already know. Studies on learning and cognition have shown that it's difficult for any learner to really learn something if they can't connect it to something they almost already know. A problem arises when students' present world views are not consistent with what they are attempting to learn. Redish [24] describes a cognitive model of student learning and provides teachers with a number of cognitive principles and guidelines for physics instruction. The five general principles he outlines are:

1. The constructivisim principle

2. The context principle

3. The change principle

4. The individuality principle

5. The social learning principle (p. 30)

In addition to these guiding principles, Redish also provides a number of associated corollaries. It is the individuality principle that provides additional motivation for the PNM course design. In describing the individuality principle Redish says “Let's figure out what the students know and provide them with a learning environment lectures, demonstrations, labs, and problems - that takes them from where they are to where we want them to be. Since we all know that a few students get there from here using our current procedures, why can't we make it work for all of them?” (pp. 36 - 37). Redish further argues that the individuality principle is a word of warning that tells us we should not be looking for a "magic bullet" (p. 37). Redish's individuality principle states "Since each individual constructs his or her own mental structures, different students have different mental responses and different approaches to learning. Any population of students will show a significant variation in a large number of cognitive variables” (p. 37). He also suggests that the large standard deviation obtained in so many educational experiments is not experimental error; rather, it is a part of the result.

Because of their lives' experiences, each student has constructed her/his own mental model of how the world works, i.e. their own individual world view. What is clear is students attempt to make linkages to what they already know. Redish suggests that students draw different con- clusions based on their individual experiences and as a result, will have varied methods of approach. Redish summarizes this fact in Corollary 4.1 which states "People have different styles of learning” (p. 37). Certainly a given physics activity cannot be expected to cater to every student's unique style of learning. That is clearly not the goal of research on individual learning styles. Alternatively, individual styles of learning are possible to measure and can provide both the student and the teacher with powerful information about their impact on student learning. A great deal of the format for the physics course and the associated formative assessment techniques were created with the individual styles of learning of the student clientele in mind.

\section{Brief Overview of Course Design and Student Clientele}

The course to be described is a second-level physics course for non-majors entitled Physics for a New Millennium (PNM) at American University (AU). PNM was developed by the author in 1998 and its foundation has evolved through continuous adaptation of existing results from studies in the field of Physics Education Research (PER). In addition to the resources noted earlier, research involving workshop and studio-based courses including the Workshop Physics course developed by Priscilla Laws (Dickinson College) [25] and the Student-Centered Activities for Large Enrollment University Physics (SCALE-UP) project pioneered by Bob Beichner, et al. (North Carolina State University) [26] have served to help frame the course design. A significant outcome of these and other PER studies is; in comparison to more traditional instructional strategies, student conceptual understanding and problem-solving ability is enhanced within an activity-based learning environment [27 - 31].

PNM is a course that many students take to satisfy the University's General Education requirements towards graduation. All students at AU must take two introductory science courses, one of which must have a laboratory component. Students who enroll in PNM have all typically taken a first-level physics course that included a laboratory experience. A unique element of the PNM course is its active learning format along with its focus on student writing as an alternative method of assessment. This form of assessment is in contrast to more conventional classroom measures and to numerous research-based normalized tests and surveys such as the Force Concept Inventory (FCI), the Force-Motion Concept Evaluation (FMCE) the Mechanics Baseline Test (MBT), and others [32 - 37].

In the following section, an overview of the curriculum covered in the PNM course is outlined. In addition, a description of the course format and a sampling of the kinds of interactive engagement activities that students perform are discussed.

\section{CURRICULUM OVERVIEW}

The curriculum for the second-level PNM course includes the following topic areas which are quite typical in a second-level course:

- sound and waves,

- electricity and magnetism (E \& M),

- light and color,

- optics, and (time permitting)

- introductory modern physics. 
PNM is taught in an integrated lab-lecture format where the topics are presented in such a way so as to allow students maximum opportunity to engage with the material. The course consists of one 75-minute period each week where course content is delivered in an interactive lecture format. The second weekly period is a doubleblock period and hence is 150 minutes in length. The double-block period is designed to give students a good deal of time to perform hands-on activities and experiments within a team-based environment. Because of the unique nature of the course, the class is limited to 16 students. The spring 2012 class enrollment was actually 17 students. Many of the students who enroll in PNM intend to pursue a minor in Applied Physics. The spring 2012 enrollment was increased to accommodate the scheduling needs of one of the Applied Physics minors.

Throughout a given semester, students have an opportunity to perform numerous hands-on activities designed to give them multiple opportunities to interactively engage with the course content. Some interactive projects are structured in a more traditional lab-type format. Many other activities are structured in such away so as to provide students with an opportunity to pursue inquiry and investigation using a variety of techniques. During most double-block class sessions the students work together as a team to probe new concepts and take on new challenges. Figure 1 shows students working and brainstorming during a typical class session.

One of the first topics to be studied is sound and waves. Figure 2 shows students investigating sound properties using a vacuum pump and bell jar. By pulling a vacuum on the bell jar, students quickly learn that sound needs a medium for propagation.

Additional activities involving sound and waves include the determination of the speed of sound in air using multiple venues and an investigation of standing waves on a string. After multiple investigations of sound and waves, the next set of activities in the PNM course involves electricity and magnetism.

Within the electricity and magnetism course module students perform a number of hands-on investigations which include:

- electrostatics,

- electric circuits,

- incandescent light bulb and 3-way bulb dissection,

- electric motor-building, and

- superconductors.

Both the electrostatics and the electric circuits activities are performed using a team approach. Figure 3 illustrates how the various teams of students work together on some of the electrostatics activities.

Each time a new set of activities is performed, new teams are created. By the end of the semester, each student has worked with every other student in the class several times. The investigations involving incandescent light bulbs are done in an integrated team and whole-class approach. Part of the time the students work with their partners to take the necessary measurements. At other times, the teams are brought together to discuss their measurements as a class and to make conclusions based on those measurements.

The motor-building activity is done individually. Each student is given a motor kit and works individually to build a working motor. In Figure 4 (next page), students

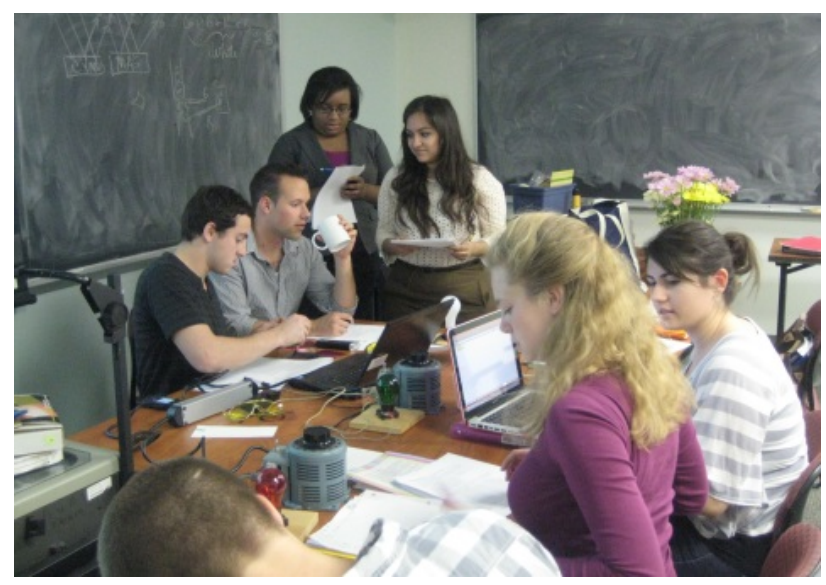

Figure 1. Students use the team approach to tackle new concepts and work through projects and activities.

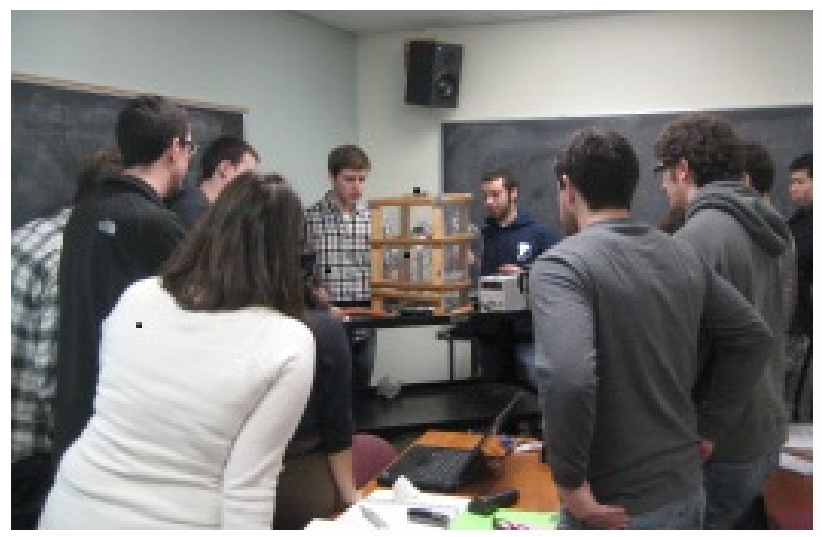

Figure 2. Students investigate the properties of sound.

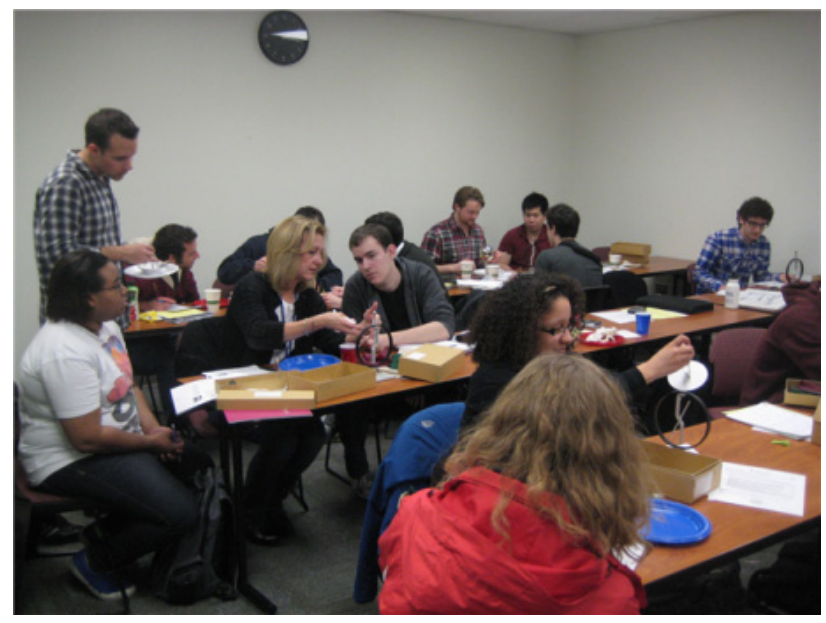

Figure 3. Teams of students performing electrostatics activities.

are working independently to build their motors. At the end of the activity the students are allowed to keep the motors they have constructed. The first person to get their motor to function properly often "wins" a small physics prize. While this activity is done individually, there is typically a significant amount of group interaction as students have learned the importance of teamwork by this point in the semester!

Once students have a firm foundation in the broad topics within the content areas of $\mathrm{E} \& \mathrm{M}$, they move on to investigate the topics of light, color, and optics. Using 
their knowledge of E \& M as a springboard, students work to understand the nature of light and color. For example, students spend time understanding the difference between mixing colored lights and mixing colored pigments. As Figure 5 illustrates, students also perform activities that allow them to understand the colored display on a computer monitor.

One of the students' most memorable activities involves a demonstration of a superconducting material. This activity involves the use of liquid nitrogen to cool the small superconducting wafer along with a very strong magnet.

The above examples are but a few illustrations of the wide range of hands-on activities the students taking the PNM course have an opportunity to work with. One of the outcomes of these types of interactive engagement activities is the opportunity to learn about relevant topics in physics using a "non-cookbook" format. In addition, students have numerous opportunities to work in a team environment; and, as a result, quickly learn the benefits of cooperative learning.

Regardless of the activity, the class as a whole functions as a team. The team does not move on to a new activity until all class members have completed the current activity. The end result is, as students finish a particular activity, they move into the role of teaching assistant, and work to ensure that all of their classmates have fully completed a task or set of tasks. In this way, everyone's class time is utilized to the fullest extent possible. As Figure 6 helps to reveal, moving into the role of teaching assistant really aids students in solidifying their own conceptions of what is taking place within a given activity or set of activities. Instructor observation of the students at work in this type of team environment provides multiple data points for more authentic and holistic views of what the students are actually learning.

In addition to the many opportunities to interactively engage with the course content through hands-on activities, the students also have an additional and perhaps more unique opportunity to interact with the material. This opportunity comes in the form of preparing and presenting of a formal scientific research paper presented at a conference held on the last day of class. In the following section, an overview of the conference paper activity is outlined. In addition, details about the structure of the activity along with project milestones and relevant examples will be provided.

\section{THE CONFERENCE PAPER}

The laboratory component of the first-level course requires students to prepare a formal written laboratory report each week. Rather than repeat the written laboratory report experience that students had in the first-level course, PNM provides students an alternative, and perhaps more authentic means for demonstrating their understanding of the physics content being studied. This alternative learning experience comes in the form of a written scientific research paper. Before the conference paper activity is formally described, perhaps we should ask the question

\section{A. Why Have Students Write in a Physics Class in the First Place?}

In recent years, a number of writing techniques have evolved that make use of various writing-to-learn strate-

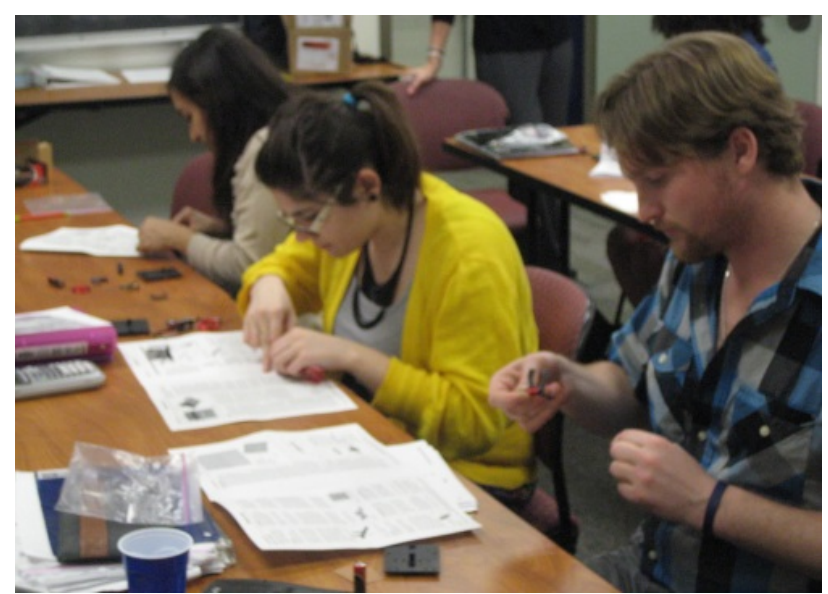

Figure 4. The motor-building activity.

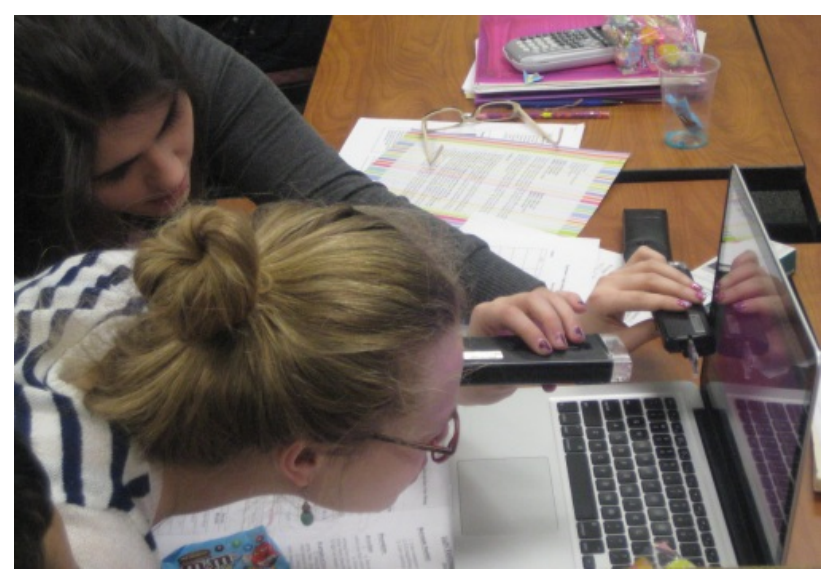

Figure 5. Students investigate color using a computer monitor.

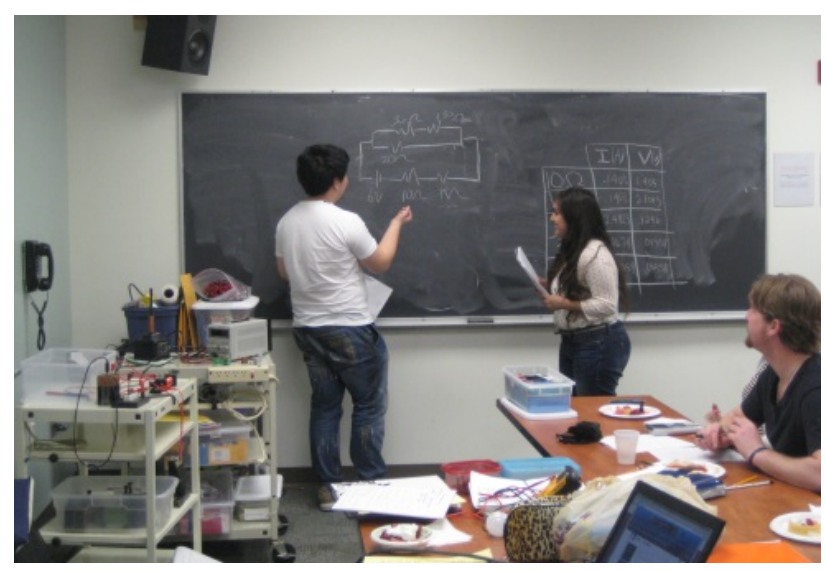

Figure 6. Team members work as TAs to assist other class members.

gies within the domains of STEM education [38 - 50]. The use of writing in introductory classes for non-majors (andmajors) may be an effective vehicle for allowing students to enhance their critical thinking and problemsolving skills. Writing can also assist students with the identification and confrontation of personal misconceptions [51]. For the instructor, errors made within these writing activities can be more revealing in terms of what students are really thinking, and provide additional information on their conceptual model-building more so than can errors made on typical multiple choice or other tests.

Science classes are oftentimes seen by many students to be threatening and intimidating places to be. Tobias [52] 
has been critical of introductory college science courses and has argued that typical classrooms are “... competitive, selective, intimidating, and designed to winnow out all but the 'top tier' ... there is little attempt to create a sense of 'community' among average students of science” (p. 9). Hence, a traditional science classroom may present potential barriers that could inhibit learning for some students. The active process of writing may provide one mechanism through which these barriers to learning could be reduced and possibly even removed. Tobias [53] also indicates that writing can serve as a means to help students relieve their anxiety and help them unlearn models and techniques that have been shown to be scientifically unsound.

The strategy to be highlighted here involves a writing technique developed to bring science and engineering topics to the forefront as students are learning about key physics topics in a second-level course. One goal of the conference paper project is to help make physics seem less intimidating to students - particularly those in the 'second tier' - while simultaneously increasing the rigor of the course. The technique employed in the PNM course requires students to write and present a scientific paper to an audience of their peers. Over the course of a given semester, students are exposed to all aspects of preparing a professional paper for publication. The process includes:

- the submission of an abstract,

- the preparation of a first draft for instructor review,

- the preparation of a second draft for formal peer review, and

- the preparation of a revised, camera-ready copy for publication in the conference proceedings.

The conference paper activity begins with a formal issue of a Call for Papers.

\section{B. The Call for Papers}

At the very beginning of the semester, students are informed that they will have an opportunity to write a formal scientific research paper for publication in a class conference proceeding, and for presentation in a class conference to be held at the end of the semester. Specific details about the conference paper activity are provided to the students on the first day of class. Students are told that by the end of the term they will have produced a scientific paper of publishable quality. Students in the PNM class are made aware of the importance of strengthening their written and oral communication skills by focusing on a discussion of the expectations that employers and graduate schools have in terms of students' overall ability to communicate. Students are told that employers will often ask for a writing sample during a job interview. They are brought to understand the value of producing an end product that will have potential future importance for them. From the very beginning of the paper writing process the students tend to embrace the activity with energy and passion. Moreover, the students understand that this activity is much more than the instructor assigning homework so that they have something to attach a grade to.

As was outlined in the previous section, students are allowed to choose a topic for their presentation that will permit them to demonstrate their understanding of a key topic area, or set of topic areas, that will be discussed in class. Students are encouraged to choose a topic that

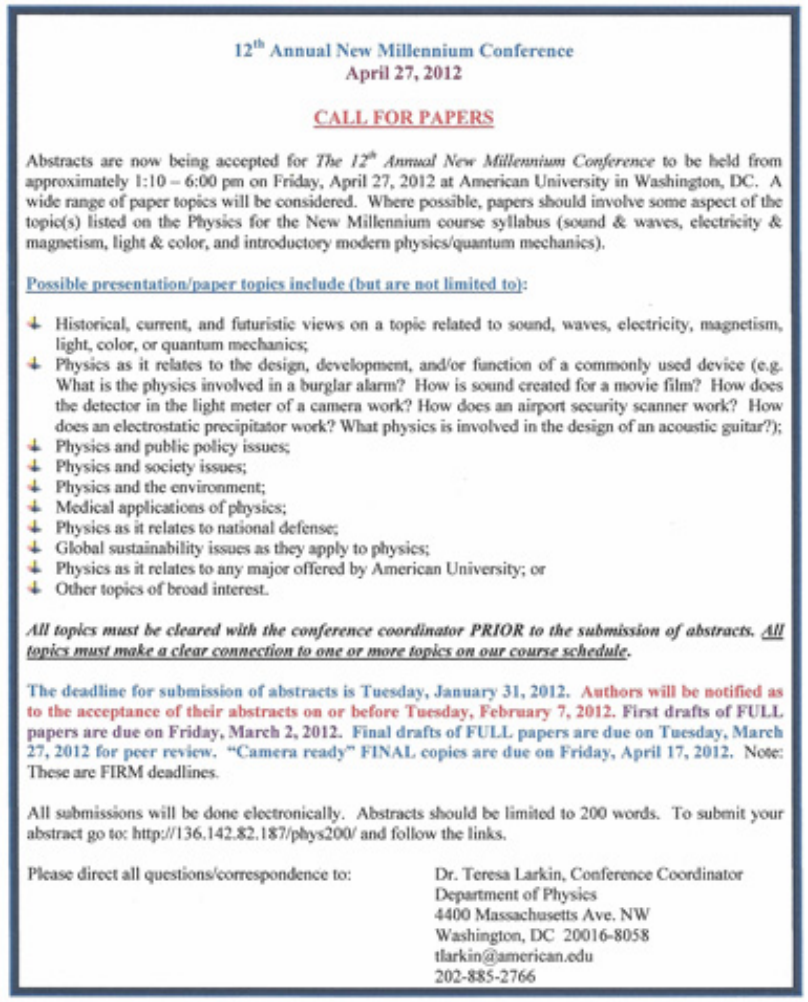

Figure 7. The conference call for papers.

might overlap with their major area of study, or something they are personally interested in and would like to know more about. The conference paper activity begins with a formal call for papers as illustrated in Figure 7.

The students have approximately two weeks to select their topic and get instructor approval for it. In some cases, the instructor works with the students to help them narrow down and refine their topic choice. Once their topic has been approved, the students respond to the call for papers by submitting an abstract to the conference web site. From this point on, all aspects of the conference paper activity mirror those of an actual professional conference. The only difference is that no student papers are rejected at the abstract phase.

Approximately one week after the submission of abstracts, students are notified that their abstracts have been "accepted." Students are then "invited" to submit a first draft of their paper by a date set towards the midpoint of the semester.

\section{Preparation and Submission of First Draft for Instructor Review}

One requirement during this phase of the process is that students meet with the instructor individually to talk about the focus of their papers. Quite often students tend to try and cover too much material when they begin their research. The instructor works with them to help them narrow and focus their research into a manageable amount. During this discussion, considerable attention is given to the type and nature of the resource material that the students have gathered. One requirement of all students it that they must make use of the physics textbook used in the course as a solid reference in their papers. Paul Hewitt's Conceptual Physics is the textbook of choice for the course [54]. 
Once the abstract submission and acceptance phase is completed, students spend approximately $6-7$ weeks preparing the first draft of their full papers. Students must follow a formal set of guidelines as they prepare their first drafts, similar in nature to those used for the IGIP conference. Figure 8 shows the first page of the formatting guidelines that are distributed to the students as they begin working on the first drafts of their research papers.

The length requirement for the research papers is six formatted pages. This requirement is comparable to a standard 15 - 20 page, 12 pt font, and double-spaced research paper. For the first draft, students are required to submit five fully-formatted pages.

Students submit the first drafts of their papers at the midpoint of the semester, which coincides with AU's spring break. The first drafts of the papers are reviewed by the instructor. The instructor provides each student with individual reviews of their paper and does so in a professional format. At this stage of the conference paper activity, the instructor's goal is two-fold:

1. to provide students with concrete feedback so that they might revise their papers and prepare a $2^{\text {nd }}$ draft; and

2. to serve as a model that students can refer to when they conduct their peer reviews.

Once students receive their instructor feedback, they receive a formal email from the instructor and are invited to submit their full papers for peer review.

\section{Preparation and Submission of Second Draft for Peer Review}

The next phase of the conference paper activity involves the preparation of a second paper draft that is submitted for peer review. Except for the fact that the papers are not blind-reviewed, this phase of the activity mimics that of a professional peer review process. Students are given a set of guidelines for the peer review and are instructed to provide detailed comments on the paper that they've been assigned. Students spend approximately three weeks working on the second draft of their papers and are given one week to complete the peer review. Each student is assigned one paper for peer review.

In terms of assessment, the peer review activity is graded independently and is worth approximately $5 \%$ of their overall course grade. Once the peer review process has been completed students have about three weeks to complete and submit their final "camera-ready" copy.

\section{E. Preparation of Final "Camera Ready" Copy}

Camera-ready copies of students' final papers are organized by session topic and "published" in the proceedings for the class conference. Each student is given a copy of the proceedings for inclusion in their personal dossiers. Students are encouraged to list the class conference paper experience on their resumes.

The students submit their camera-ready copies approximately one week before the class conference. The 2012 New Millennium Conference was organized into five sessions as illustrated in Table I. The students' individual paper titles within each session are also displayed.

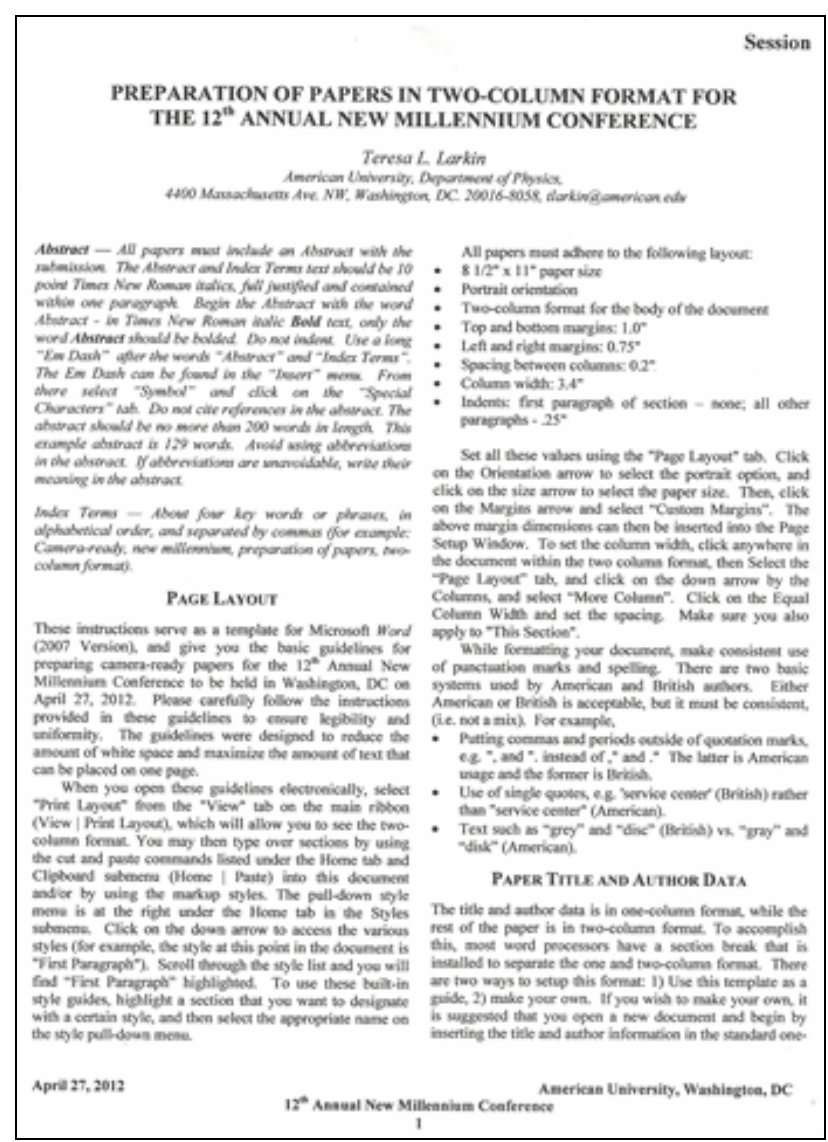

Figure 8. Paper formatting guidelines.

TABLE I.

THE 2012 CONFERENCE PROGRAM

\begin{tabular}{|c|}
\hline Session I: Conference Welcome \\
\hline Session II: The Physics of Sound I \\
\hline $\begin{array}{l}\text { - Restoring the Sense of Hearing: The Physics of the Co- } \\
\text { chlear Implant and its Effect on The Deaf Community }\end{array}$ \\
\hline - Check One, Two: The Physics of the Microphone \\
\hline $\begin{array}{c}\text { - Project Studio: Sound Absorption, Isolation, and Noise Re- } \\
\text { duction }\end{array}$ \\
\hline - The Sound of Grandeur: Spanish Colonial Architecture \\
\hline - The Whispering Gallery: Statuary Hall Unveiled \\
\hline Session III: A Potpourri of Physics \\
\hline - Combustible Physics \\
\hline $\begin{array}{c}\text { - The Physics of Photographs: An Analysis of Light and } \\
\text { Color in Print Photography }\end{array}$ \\
\hline - The Benefits of Using Lasers in Medical Procedures \\
\hline $\begin{array}{c}\text { - Powering the Future: A Look at Two Key Renewable En- } \\
\text { ergy Resources Using Electromagnetic Induction }\end{array}$ \\
\hline Session IV: The Physics of Sound II \\
\hline - The Radio Movement \\
\hline - Good Vibrations: Physics \& The Theremin \\
\hline - Unplugged: The Physics of an Acoustic Guitar \\
\hline - The Physics of the Violin \\
\hline Session V: From Energy to Electrodynamics \\
\hline - Development in the Homebuilding Industry \\
\hline $\begin{array}{l}\text { - Random Walk Theory: From Financial Markets to Electro- } \\
\text { dynamics }\end{array}$ \\
\hline - Ocean Powerhouse \\
\hline - Potential Dangers of Taser Gun Physics \\
\hline
\end{tabular}


Additional details regarding the class conference are provided in the following section. Specific details regarding the student presentations are also shared.

\section{The $12^{\text {TH }}$ AnNual New Millennium Conference}

The $12^{\text {th }}$ Annual New Millennium Conference was held on Friday, April 27, 2012 which was the last day of the PNM class for the spring term. The conference ran from approximately $1-6 \mathrm{pm}$. Students were informed on the first day of class that the conference activity would take longer than a typical 150-minute Friday class period. Earlier in the term students were given one class period off to make up for the longer class on the day of the conference. Students that had other classes to attend during the conference time period were allowed to do so. Once their class was over, they returned to the conference activity.

The instructor served as the moderator for the conference. Each student was given 10 minutes to present their papers with two additional minutes reserved for questions. Two days prior to the conference, the instructor set aside a full day to listen to and provide feedback on each of the student's PowerPoint presentations. One of the benefits of doing these "practice runs" was to help to ensure that the students' presentations adhered to the ten minute time limit and to ensure that the presentations were done in professional manner. In addition, the students quickly learned the importance of focusing their presentations on the key items covered in their papers.

After spending a full semester working on their papers, the students' passion towards the project tends to increase exponentially. As a result, the students want to include absolutely everything in their presentations. When they come for their practice sessions, many students often have a 20 - 30 minute presentation that they have prepared! Given the fact that they will only have 10 minutes to give their presentations, they quickly learn the value of practicing ahead of time! The end result was a class conference that, in all respects, was very professional executed. Figure 9 is a snapshot of one of the students presenting her paper at the conference.

In addition to the members of the class, attendees at the conference included friends and family members of the student participants, physics faculty and students, and staff members from the AU community. Approximately half way through the conference a reception was held and refreshments were provided. This conference event has grown in magnitude and has become a showcase event for the Department of Physics.

One of the objectives of the conference paper activity is to provide students with a meaningful real-world experience. A second objective is to provide the instructor with a more authentic assessment measure that could be used in tandem with more traditional measures like exams and quizzes.

\section{Assessment OF CONFERENCE PAPER}

Authentic assessment involves the use of activities and tasks that involve replicas of those which are faced by adults in the professional world [55]. Furthermore, authentic assessment involves providing activities, problems, or questions of importance that require students to use their knowledge to fashion performances both effectively, and creatively. Creation and use of a rubric to evaluate student performance is common within the domain of authentic assessment.

Each phase of the paper writing process was assessed. Students were earning points towards their overall conference paper grade at each milestone of the activity. A rubric was created that provided the details for the distribution of points throughout the activity. The assessment rubric for the conference paper is shown in Figure 10. Overall, the conference paper activity constituted approximately $30 \%$ of the students' course grade.

At the beginning of the term, students are informed that throughout each phase of the project they will be "banking” points towards their overall conference paper grade. Armed with this information, students are empowered as they complete each phase of the activity. Each phase of the activity also provides the instructor with a way to more clearly chart each student's overall learning in a deeper and more robust way. For example, during the peer review process, the instructor gains valuable information about student understanding based on the nature of the com-

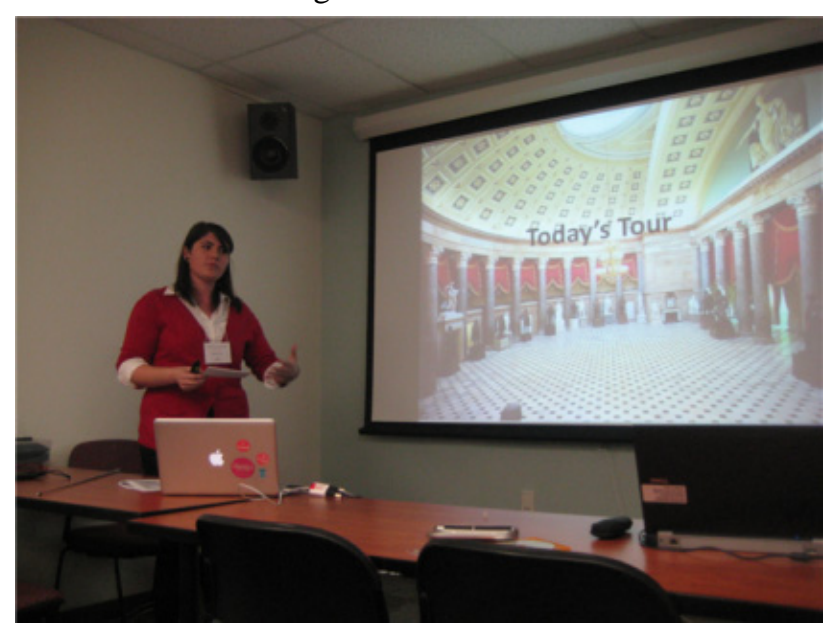

Figure 9. A student presentation at the $12^{\text {th }}$ Annual New Millennium Conference.

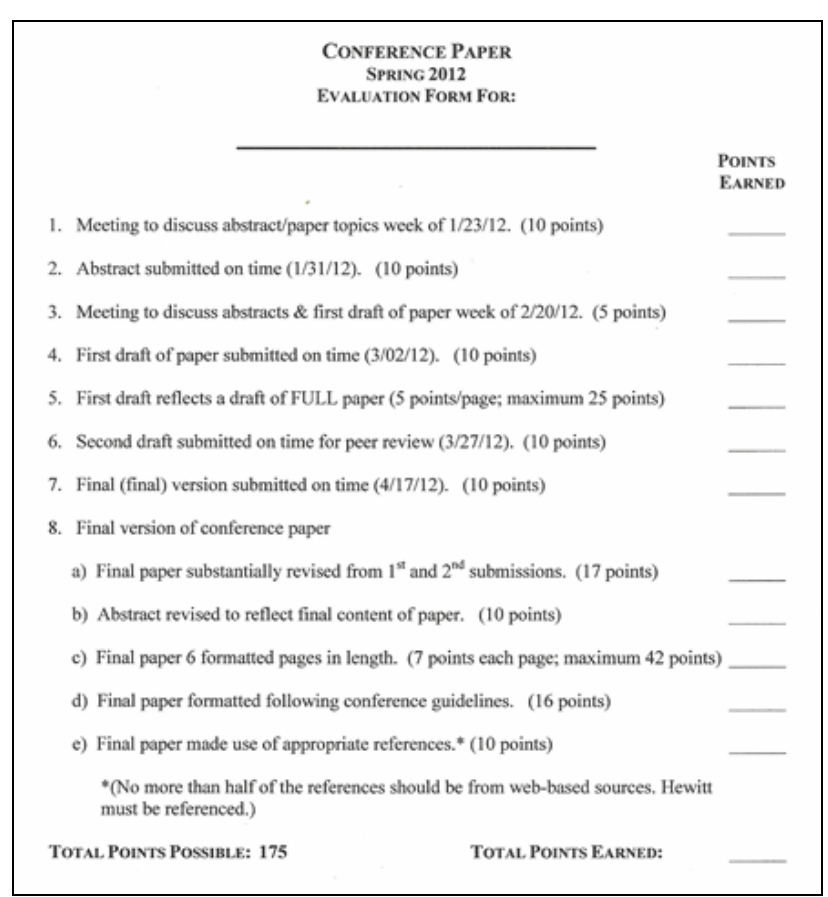

Figure 10. Assessment rubric for conference paper activity. 
ments and feedback the students provide to their classmates. Traditional pencil and paper exams often do not provide as complete a picture of the true level and depth of a students' understanding about a topic or set of topics.

From both the instructor and student perspective the conference paper activity is a "win-win." The instructor gets a chance to add an alternative and more authentic assessment tool to the course design; and, the students have a chance to produce a scientific research paper that has the potential to do much more than simply help them learn physics. Feedback received from the students epitomizes the value they place on the conference paper project.

\section{STUDENT FEEDBACK}

Feedback from the students was overwhelmingly positive. Students appreciated the fact that they were able to connect the physics they were learning with their majors or with other areas and topics that they were interested in studying. For example, Student A, a Sociology major with an Applied Physics minor wrote a paper entitled "Restoring the Sense of Hearing: The Cochlear Implant and its Effect on the Deaf Community." Within this paper, the student researched cochlear implants, which are electronic devices designed to restore hearing for deaf individuals. She was able to couple her research to include a focus on the controversies they have caused among deaf individuals. Regarding the paper-writing activity, Student A indicated that "The paper assignment for PNM presented many challenges that all contributed to my general learning. To write a paper on the physic terms I was learning within such specific guidelines required mastering the key physic concepts. The experience taught me to write in a way that would be educational to the reader. Proofing a classmates' paper helped me critically look at a paper and by finding errors in their paper I was able to find more items to correct in my own paper [personal communication, August 26, 2012."

Student B was able to apply his research on Spanish colonial architecture to his major. As an International Relations major and Spanish minor he was able to conduct research that allowed him to look at how the physical design of a structure can influence the activities conducted inside that building. He was also able to explore ways that the architecture has changed over time; and, make a connection to broader societal changes.

As a Business Administration major with a minor in Applied Physics, Student C investigated the physics of light and color with an emphasis on color photography. In terms of the overall paper process, she noted "At first I was a bit skeptical about the process. It sounded like a very difficult task to accomplish and I was nervous about getting it done. I was very unfamiliar with my topic before I began the paper, which was the physics of light and color. But by spending time learning about the history of how scientists developed theories around the physics of color and of light, the task of writing a paper did not seem as difficult. Writing the paper took a while, but I also enjoyed our peer reviews. Having someone else read my paper helped give me new ideas on where to go.”

In terms of the research component of the activity, Student C further suggested, "Writing this research paper was a very rewarding process that helped me grasp key physics concepts that I had previously known nothing about. I was able to learn key physics concepts not only by doing experiments, but by studying the history of where they came from. By learning about the history behind the source of key physics concepts like Maxwell's equations, I was better able to understand these concepts in the classroom. I feel that by writing this paper, it was easier to learn key concepts. Having to write down what I was learning forced me to make connections between all this new material I was learning, and what I had previously known. By writing this paper, it was easier for me to connect all this new knowledge I was learning to the basic principles I had known. "As for the overall experience of writing the physics research paper and presenting it at the class conference, Student C said I very much enjoyed writing this paper. Research is a tough, yet rewarding process. I feel like I was able to become very well versed in the physics behind light and color. After writing the paper, I felt more comfortable discussing this topic in class and with my peers [personal communication, August 21, 2012]."

Other students, like Student D, used the conference as an opportunity to research something completely different from their area study. With a major in Music, Student D researched the physics of the internal combustion engine. In his research he was able to compare the internal combustion engine used in a vast majority of automobiles to those used in electric-powered cars. In an interview for an article written to highlight the PNM conference experience which was showcased on the College of Arts and Sciences website, Student D noted that "Compared to electrical engines, internal combustion engines are incredibly inefficient Only ten percent of the gasoline you put in your car is actually used for moving the car forward [56].”

One of the author's goals in having students prepare a formal research paper was to give them an opportunity to conduct research that would be interesting. In addition, the experience simultaneously allowed students to uncover, on their own, links between physics and their major or other interest area. Sometimes, when students take a physics course they have difficulty relating the topics studied to real-world situations and applications. The research paper helped give a more authentic voice to the physics the students were learning about in the classroom.

\section{VIII.SUMMARY}

As students move towards graduation and begin the process of applying to graduate schools and/or start to look for employment, they repeatedly find enormous value in the conference paper activity. Students quickly realize the importance of sharpening their written and oral communication skills. Having an opportunity to write and present a scientific research paper also serves to give the instructor material to use when writing letters of recommendation for the students.

A significant goal of the activity was to provide students with an authentic experience in which they could demonstrate to the instructor that they had a solid understanding of the physics content covered during the term. The conference paper activity clearly provided the instructor with more meaningful and robust information about student learning. Because each milestone of the activity had an assessment component, the instructor was often able to help students to correct a flaw in their thinking while the learning was actually taking place. More tradi- 


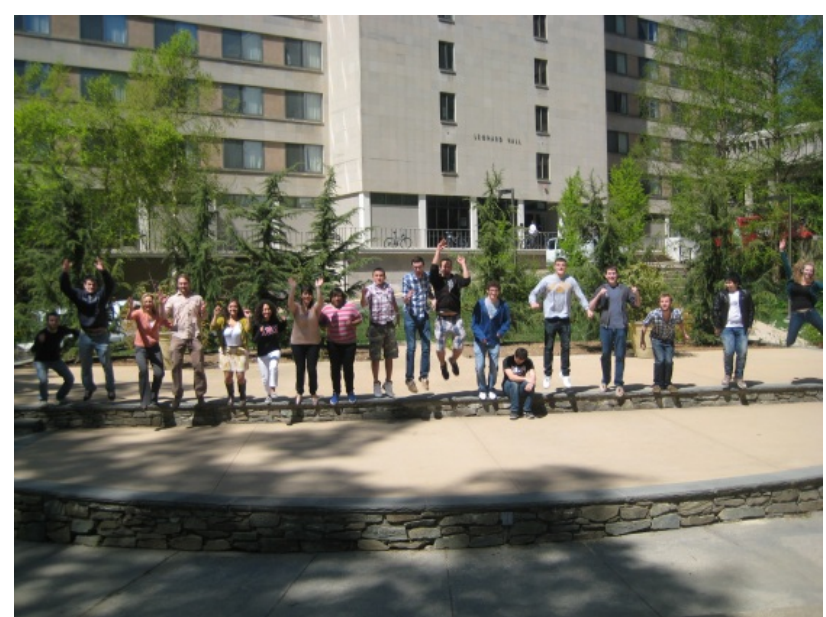

Figure 11. The 2012 PNM class.

tional assessment measures like exams and quizzes are typically given "post mortem" and therefore do not have a built-in mechanism to correct flawed thinking like authentic, formative measures do. The conference paper activity provided students an opportunity to demonstrate, at a deeper level, their understanding of physics while simultaneously providing them with a learning experience that would serve them well, long after the semester was brought to a close.

\section{ACKNOWLEDGMENT}

The author wishes to thank the students from her 2012 PNM class. You demonstrated your dedication and willingness to learn new and difficult material throughout each stage of the paper writing process. As figure 11 shows, your energy, passion, and yes ... sense of humor ... were demonstrated every class period.

Thank you for allowing me to take so many pictures and for lovingly allowing me to showcase your passion towards physics through the writing of this paper.

\section{REFERENCES}

[1] Jones, T. H. and Paolucci, R. (1998). The learning effectiveness of educational technology: A call for further research. Educational Technology Review, (9), 10 - 14.

[2] Deslauriers, L., Schelew, E., and Wieman, C. (2011). Improved learning in a large-enrollment physics class. Science, 332, $862-$ 864. http://dx.doi.org/10.1126/science.1201783

[3] Smith, M. K., Wood, W. B., Adams, W. K., Wieman, C., Knight, J. K., Guild, N., and Su, T. T. (2009). Why peer discussion improves student performance on in-class concept questions. Science, $\underline{323}, 122$ - 124. http://dx.doi.org/10.1126/science.1165919

[4] Mazur, E. (1997). Peer instruction: A user's manual. Upper Saddle River, N.J.: Prentice Hall.

[5] Hammer, D. (1989). Two approaches to learning physics. The Physics Teacher, 27(9), 664 - 670. http://dx.doi.org/10.1119/ $\underline{1.2342910}$

[6] Van Heuvelen, A. (1991). Learning to think like a physicist: A review of research-based instructional strategies. American Journal of Physics, 59(10), 898 - 907. http://dx.doi.org/10.1119/ 1.16668

[7] Hestenes, D., Wells, M., and Swackhamer, G. (1992). Force concept inventory. The Physics Teacher, 30(3), $141-153$. http://dx.doi.org/10.1119/1.2343497

[8] Maloney, D. (1994). Research on problem solving: Physics. In D. L. Gabel (Ed.), Handbook of Research on Science Teaching and Learning (pp. 327 - 354). New York: Macmillan Publishing Company.
[9] Reif, F. and Scott, L. A. (1999). Teaching scientific thinking skills: Students and computers coaching each other. American Journal of Physics, 67(9), $819-831$. http://dx.doi.org/10.1119 $\underline{11.19130}$

[10] Arons, A. B. (1990). A guide to introductory physics teaching. New York: John Wiley \& Sons.

[11] Halloun, I. A. and Hestenes, D. (1985). The initial knowledge state of college students. American Journal of Physics, $\underline{53}(11)$, 1043 - 1055. http://dx.doi.org/10.1119/1.14030

[12] McCloskey, M., Caramazza, A., and Green, B. (1980). Curvilinear motion in the absence of external forces: Naïve beliefs about the motion of objects. Science, 210, 1139 - 1141. http://dx.doi.org/10.1126/science.210.4474.1139

[13] McDermott, L. C. (1984). Research on conceptual understanding in mechanics. Physics Today, 37, 24 - 32. http://dx.doi.org/10.1063/1.2916318

[14] McDermott, L. C. (1991). A view from physics. In M. Gardner, J. Greeno, F. Reif, A. H. Schoenfeld, A. diSessa, and E. Stage (Eds.), Toward a scientific practice of science education (pp. 3 30). Hillsdale, NJ: Lawrence Erlbaum Associates.

[15] Hammer, D. (1996). More than misconceptions: Multiple perspectives on student knowledge and reasoning, and an appropriate role for educational research. American Journal of Physics, 64, 1316 1325. http://dx.doi.org/10.1119/1.18376

[16] Reif, F. (1995). Millikan lecture 1994: Understanding and teaching important scientific thought processes. American Journal of Physics, 63(1), 17 - 32. http://dx.doi.org/10.1119/1.17764

[17] Astin, A. W. (1993). Assessment for excellence: The philosophy and practice of assessment and evaluation in higher education. Phoenix, AZ: American Council on Education and the Oryx Press.

[18] Rebello, N. S. (2009). Can we assess efficiency and innovation in transfer? AIP Conference Proceedings, 1179, 241 - 244. http://dx.doi.org/10.1063/1.3266726

[19] Beichner, R. J. (2009). An introduction to physics education research. In C. Henderson and K. A. Harper (Eds.), Getting started in PER. College Park, MD: American Association of Physics Teachers.

[20] Redish, E.F. (2003). Teaching physics with the physics suite. Hoboken, NJ: John Wiley \& Sons.

[21] Knight, R. D. (2002). Five easy lessons: Strategies for successful physics teaching. San Francisco, CA: Addison-Wesley.

[22] See Ref. 4.

[23] Hewson, P. W. (1996). Teaching for conceptual change. In Treagust, D. F., Reinders, D., and Fraser, B. J. (Eds.), Improving teaching and learning in science and mathematics. New York: Teachers College Press.

[24] See Ref. 20.

[25] Laws, P. W. (1991). Calculus-based physics without lectures. Physics Today, 44(12), 24 - 31. http://dx.doi.org/10.1063/ 1.881276

[26] Beichner, R. J., Saul, J. M., Allain, R. J., Deardorff, D. L., and Abbott, D. S. (2000). Introduction to SCALE-UP: StudentCentered Activities for Large Enrollment University Physics. Proceedings of the Annual Meeting of the American Society for Engineering Education, Seattle, Washington, Session 2380.

[27] Hake, R. R. (1998). Active-engagement vs. traditional methods: A six thousand student study of mechanics test data for introductory physics courses. American Journal of Physics, 66(1), $64-74$. http://dx.doi.org/10.1119/1.18809

[28] Cummings, K., Marx, J., Thornton, R., and Kuhl, D. (1999). Evaluating innovation in studio physics. Physics Education Research: A Supplement to the American Journal of Physics, 67(7), $\mathrm{S} 38$ - S44.

[29] Thornton, R. and Sokoloff, D. (1990). Learning motion concepts using real time microcomputer-based laboratory tools. American Journal of Physics, 58(9), $858 \quad-867$. http://dx.doi.org/10.1119/1.16350

[30] Redish, E. F. and Steinberg, R. N. (1999). Teaching physics: Figuring out what works. Physics Today, 52(1), $24-30$. http://dx.doi.org/10.1063/1.882568 


\section{THE EVOLUTION OF AsSESSMENT WITHIN AN INTRODUCTORY PHYSICS COURSE}

[31] Van Heuvelen, A. (1991). Overview, case study physics. American Journal of Physics, $\underline{59}(10), \quad 898 \quad-906$. http://dx.doi.org/10.1119/1.16668

[32] Larkin-Hein, T. (2001). Writing as a teaching and learning tool in SMET education. Journal of SMET Education: Innovations and Research, 2(2/3), $25-35$.

[33] Larkin, T. L. (2009). Give it a 'TWIST!' Turning writing into student thinking. IEEE/ASEE Frontiers in Education Conference, Austin, Texas. Electronic proceedings, Session T4C, pp. $1-4$. IEEE Catalog Number: CFP09FIE. ISBN: 978-1-4244-4715. Library of Congress: 79-640910. ISSN: 0190-5848.

[34] Larkin, T. L., (2007). Writing: A global Active learning tool in STEM education. International Conference on Engineering and Computer Education (ICECE 2007), Santos/Monguaguá, Brazil, Plenary Session II.

[35] Kalman, C. S. (2007). Successful science and engineering teaching in colleges and universities. Bolton, MA: Anker Publishing Company, Inc.

[36] Larkin, T. L. (2011, March). The inclusive classroom: A researchbased approach to enhance learning. Invited paper at the 40th IGIP International Symposium on Engineering Education, São Vicente at the Metropolitan region of Baixada Santista, Brazil.

[37] Larkin, T. L. \& Budny, D. (2008). Peer review from a student perspective. IEEE/ASEE Frontiers in Education Conference, Saratoga Springs, New York. Electronic proceedings, Session F2C, pp. 14 - 15. IEEE Catalog Number: CFP08FIE-CDR. ISBN: 978-14244-1970-8. Library of Congress: 79-640910. ISSN: 0190-5848.

[38] Connolly, P. \& Vilardi, T. (1989). Writing to learn in mathematics and science. New York: Teachers College Press.

[39] Countryman, J. (1992). Writing to learn mathematics: Strategies that work. Portsmouth, NH: Heinemann Educational Books, Inc.

[40] Hein, T. L. (1998). Using student writing as a research and learning tool. AAPT Announcer, 27(4), 79.

[41] Hein, T. L. (1999). Writing: An effective learning tool for nonscience majors. AAPT Announcer, 29(2), 114.

[42] Kirkland, W. L. (1997). Teaching biology through creative writing. Journal of College Science Teaching, 26(4), 277 - 279.

[43] Mullin, W. J. (1989). Writing in physics. The Physics Teacher, 27(5), 342 - 347. http://dx.doi.org/10.1119/1.2342788

[44] Rice, R. E. (1998). 'Scientific writing' - A course to improve the writing of science students. Journal of College Science Teaching, $\underline{27}(4), 267-272$.
[45] Sharp, J. E., Olds, B. M., Miller, R. L., \& Dyrud, M. (1999). Four effective writing strategies for engineering classes. Journal of Engineering Education, 88(1), 53 - 57.

[46] See Ref. 35.

[47] See Ref. 32.

[48] See Ref. 34.

[49] Larkin, T. L. \& Budny, D. (2008). Student writing: An active learning tool in physics and engineering education. Annual Conference of the American Society for Engineering Education, Pittsburgh, Pennsylvania (Session 2480). Electronic proceedings.

[50] Larkin, T. L. \& Budny, D. (2008). Peer review from a student perspective. IEEE/ASEE Frontiers in Education Conference, Saratoga Springs, New York. Electronic proceedings, Session F2C, pp. 14 - 15. IEEE Catalog Number: CFP08FIE-CDR. ISBN: 978-14244-1970-8. Library of Congress: 79-640910. ISSN: 0190-5848.

[51] Hein, T. L. (1999). Using writing to confront student misconceptions in physics. European Journal of Physics, 20, $137-141$. http://dx.doi.org/10.1088/0143-0807/20/3/002

[52] Tobias, S. (1990). They're not dumb, they're different: Stalking the second tier. Tucson, AZ: Research Corporation.

[53] Tobias, S. (1989). In Paul Connolly and Teresa Vilardi (Eds.), Writing to learn mathematics and science. New York: Teachers College Press.

[54] Hewitt, P. G. (2010). Conceptual Physics, 11 ${ }^{\text {th }}$ Ed. Boston, MA: Addison-Wesley.

[55] Wiggins, G. P. (1993). Assessing student performance. San Francisco: Jossey-Bass Publishers.

[56] http://www.american.edu/cas/news/new-millennium-conference2012.cfm, accessed 8-7-12.

\section{AUTHOR}

T. L. Larkin is an Associate Professor of Physics Education with the Physics Department at American University, Washington, DC 20016-8058 USA (e-mail: tlarkin@american.edu).

This article is an extended and modified version of a paper presented at the IGIP2012 conference, held 26 - 28 September 2012, in Villach, Austria. Received 28 November 2012. Published as resubmitted by the authors 28 January 2013. 